\title{
Republic of Ireland: White Paper on a new Mental Health Act
}

\author{
Response of the Irish Division of The Royal College \\ of Psychiatrists
}

\author{
Marcus Webb
}

The Irish Division of the Royal College of Psychiatrists welcomes the White Paper and the Government's intention to provide early legislation for a new mental health act. The Division appreciates the opportunity for contacts and discussions which the Department of Health provided over recent years for our views on new legislation to be communicated.

The Irish Division has made a preliminary response which highlighted issues of particular importance and this document seeks to amplify these and other points.

We particularly welcome the overall aim of providing treatment in the least restrictive conditions feasible for each individual, even when the individual's illness is so severe that it deprives him/her of understanding that they are ill. Also, in line with the European Convention for the Protection of Human Rights and Fundamental Freedoms (1950), the Council of Europe Recommendation (1983) and the United Nations Principles (1991), that each decision to detain a patient or to extend his/her period of detention will be subject to independent, objective, judicial-type review. It is also encouraging to see that there is a commitment to provide full coordination of mental health law in the republic with that of Northern Ireland.

The Irish Division also formally welcomes the proposal that Health Boards will be statutorily obliged to promote mental health and provide a comprehensive range of services for those who suffer mental disorder. A commitment to resource the range of services would also be most welcome. The Division welcomes the statutory obligation upon Health Boards to appoint a Clinical Director to each catchment area of the mental health services. The Division is strongly opposed to the suggestion that the Clinical Director is merely responsible for implementing policy as laid down by Health Board Management. We strongly recommend that Clinical Directors be required to be involved in planning and development of services in addition to their clinical coordination, in order that there is clear provision for medical involvement in these important tasks.

\section{Chapter 2. Criteria for involuntary admission}

Section 2.35

We believe that the Department has been enlightened in providing for the detention and treatment of individuals with severe mental disorder whose condition might otherwise deteriorate, in addition to those who might cause harm to themselves or other people.

The definition of mental disorder has always provided problems, and the practical solutions suggested in the White Paper appear to be well thought out and workable. The Division particularly welcomes the exclusion of personality disorder and social deviance as criteria for involuntary detention. While it is currently fashionable, and probably acceptable, to exclude addition to drugs including alcohol as criteria, there is no doubt that a small number of individuals and their families are at considerable risk from such addiction and could benefit from involuntary detention. These individuals, however, are likely also to develop mental disorder as defined in the White Paper, and could be admitted involuntarily in this way. The exclusion of perverted conduct is suggested but not discussed in the White Paper and may refer to sexual perversions. While a few such individuals may be potentially extremely dangerous to others, it is probably appropriate that they are dealt with by other means than by the Mental Health Act. The detention of children, persons with learning disability and with mental infirmity will be discussed later.

It will be important to provide for a detained patient to receive medical and surgical treatment in a general hospital. 
Chapter 3. Procedures for involuntary admission, transfers and return

\section{to hospital}

Sections 3.7-3.12

It is appropriate that the spouse or relative of the person concerned will continue to take responsibility for initiating application for involuntary admission. It would be important to ensure that a suitably trained, qualified, authorised officer of the Health Board would be available at all times to make application where a relative is unavailable or unwilling to make an application. The fallback situation of providing for application by the Garda Siochana, in the rare occasions where no spouse or authorised officer makes the application, is appropriate.

\section{Section 3.20}

The Irish Division would have preferred that the medical recommendation be made by a doctor with suitable experience in psychiatry, but understands the problems of such a requirement in more remote areas. There is concern that responsibility to transfer a person in respect of whom an application for detention has been made to an approved centre may fall to the Clinical Director at a time when he/she has little knowledge of the patient and possibly no access to him/her. The Clinical Director may be required to take responsibility for this individual throughout the procedure of seeking and obtaining a court order permitting the person to be transferred against his/her will. The Government may not appreciate how disturbed patients may be during this period and how powerless the psychiatric services may be to help the individual and his family or to prevent harm. We are concerned at the potential for long delays in this process, particularly at nights and at weekends. Many hours may elapse before such permission from the court would be obtainable, and it would appear to be more appropriate that the Gardai should always be available to assist in the transfer of detained patients where the latter showed resistance to transfer without the need for court proceedings.

Where it is proposed that application is made to the Court for various procedures under the Mental Health Act, the Division is very concerned that private matters of clinical and family relevance should not be unnecessarily exposed to the public domain in court. We realise that the intention is to protect the individual's civil rights, but to expose such normally confidential details to public view would not be in the interests of the health and good social functioning of the individual or his family. If the Courts are to be involved in this way, then we strongly suggest that such hearings be held in camera.
Sections 3.27 and 3.34

The holding of a patient in respect of whom an application and recommendation for detention have been made in an approved centre for 12 hours, within which time a decision must be made whether or not to detain the patient, is again welcome. Likewise, the legal authority to authorise nurses in approved centres to hold voluntary patients in certain circumstances for up to six hours pending examination by a doctor also appears to be a sensible and practical proposal. Likewise also the holding of a voluntary patient for 48 hours by the decision of a consultant psychiatrist within which time procedures for detention may be completed is a valuable provision.

Section 3.26

The Irish Division is very concerned that consultant psychiatrists may require authorisation by their employing authorities to detain patients under the Mental Health Act; also that employing authorities may withdraw authorisation. The Division considers that consultants, through their contracts, are empowered to admit patients according to clinical need. A consultant displaying unreliable judgement in relation to his/her patients should be referred to the Medical Council. In Northern Ireland, consultants are authorised to act under the Mental Health Act by the Mental Health Commission-and this procedure seems much more appropriate than that proposed in the White Paper.

\section{Chapter 4. Scope and duration of detention}

The Irish Division believes the proposals to be sensible and workable.

\section{Chapter 5. Review of detention orders}

We welcome the establishment of a Mental Health Review Board to review every initial decision to detain a patient and each decision to extend detention. We note that the Review Board is to take on tasks undertaken in Northern Ireland by two bodies, the Mental Health Commission and the Mental Health Tribunal. While preparation for hearings by panels of the Board will clearly occupy further time for consultants and multidisciplinary teams, this provision is necessary for patient's rights to be protected and to be seen to be protected. There is, however, particular concern in relation to hearings, which may be conducted some weeks after the detention of the patient. It is not clear in the White Paper whether the panel will review the validity of the original detention of the patient or its continued validity at the time of the oral hearing. If such an important body were to declare the original detention order invalid, then 
this decision would presumably provide strong support if not encouragement for individuals concerned to take legal action against the relative, authorised officer, doctors and possibly Garda Siochana who were involved in making the order, presumably in good faith. Such a decision of the Review Board would possibly provide "reasonable grounds" for a High Court action by the patient. One can predict under such circumstances a rapid decline in the willingness of applicants and others involved to seek detention orders, with resulting hardening of criteria for detention and further exposure to risk of the patient and those around him/her. This issue needs to be thought through carefully. The Irish Division recommends that the Review Panel be empowered to consider only continuing validity of the detention order at the time of the hearing. The Review Board will have already screened the detention orders shortly after admission. A further issue relates to who undertakes the care of a patient subsequent to an order by the Review Board releasing him/her from detention. The existing doctor/patient relationship will have been seriously undermined and it would be difficult for the same consultant to take responsibility for this patient.

The Irish Division is in agreement with the concept of the Mental Health Review Board's Panels consisting of a psychiatrist, lawyer and lay person, but because many of the decisions will involve fine clinical discrimination, it is important that individuals with extreme views or without some knowledge of the clinical situation be excluded from such bodies.

\section{Chapter 6. Consent to treatment}

Section 6.12 (ii)

Overall these provisions are practical and useful, but there is some concern that there is no provision for one or two emergency applications of electroconvulsive therapy (ECT) in life-threatening situations. This is particularly relevant in the practice of psychiatry of old age. Severely depressed elderly people with secondary physical debilitation may require urgent ECT and can respond very rapidly to relatively few applications. Delay in treatment while a second opinion by an 'approved' consultant psychiatrist is being sought would cause unnecessary suffering and may even have fatal consequences. In the Northern Irish Mental Health legislation it is possible to give emergency ECT and the Irish Division recommends that this provision is incorporated in the new Act. Second opinion could in an emergency be given by any consultant psychiatrist.
Chapter 7. Mentally disordered persons before the Courts and in custody

As the Department is well aware, there are considerable reservations among the Health Boards and among consultant psychiatrists concerning these recommendations. The Irish Division has no objection to the intentions discussed in the White Paper under these proposals. It is acknowledged that some individuals with mental disorders can become involved in the criminal justice system almost by default and it is their mental disorder which is the matter of primary concern. Such individuals would indeed be best managed in appropriate facilities as out-patients, day-patients and or as in-patients along with other mentally disordered individuals.

Many of the concerns of psychiatrists have been met by the provision that a report may be made, as in Northern Ireland, by the involved consultant psychiatrist, to the court, and by the exclusion of personality disorder, social deviance and substance misuse as mental disorders for purposes of involuntary detention. However, we understand in this connection that the court would act in recognition of the consultant's report and not in opposition to it. In other words, there is considerable anxiety that the courts might disregard the reports of consultant psychiatrists to the detriment of the mental health services. Many advantages have been gained for patients by providing open-door units, which should not be lost as a result of new legislation providing for court referrals. Legislation to empower courts to refer to the ordinary mental health services would add considerable urgency to the need to provide interim regional secure units ('special psychiatric centres') to which the ordinary services would have ready access for transfer of any highly disturbed individual.

\section{Chapter 8. Adult Care Orders}

\section{Sections 8.6 and 8.11}

While the proposal for an Adult Care Order is welcomed by the Irish Division, its inclusion in Mental Health legislation means that it will be of limited use to elderly people who are subjected to elder abuse. It has been documented that many such people do not suffer from a mental disorder and, therefore, could not be protected by an Adult Care Order. The Division would prefer that such a provision be included under general rather than Mental Health legislation.

\section{Chapter 9. Information, representation and Legal Aid \\ The Division accepts these proposals.}




\section{Chapter 10. Protecting mentally disordered patients}

Sections 10.3-10.8

The Division agrees with the aim of providing quality assurance in the mental health services, but we would prefer to see an advisory panel to include consultant psychiatrists and other mental health professionals working in the services and including the specialities of psychiatry. This panel might be under the chairmanship of the Commissioner for Mental Health Services, who should be a consultant psychiatrist and whose method of appointment and fixed duration of tenure should be generally agreed between the concerned organisations. The Division is very concerned that the power and influence of one Commissioner/Adviser to the Government should not be disproportionate.

\section{Sections 10.13-10.17}

The Division approves of the proposal to increase the accessibility and efficiency of the ward of court proceedings and looks forward to the introduction of the enduring powers of attorney bill. The Division also agrees with other recommendations made under this heading for the protection of patients, but comment has already been made in relation to legal actions taken as a result of decisions by the Mental Health Review Board.

Sections 10.21-10.22

The Division agrees that the term bodily restraint' requires re-definition. In practice, a small number of patients, generally detained patients, are restrained for the purposes of medical or surgical treatment or to prevent injury to himself/herself or others. On occasions such patients might be restrained by nursing or medical staff from leaving the ward for fear of injury resulting. Restraint involves in most cases the staff member or members holding the patient in the least aggressive manner possible. While some such situations, such as the giving of an injection without the patient's consent, may be predictable and may be ordered by medical staff, other occasions may not be predictable, but could be recorded in detail later.

\section{Children's services (Chapters 2 and 3)}

The issue of marrying legislative directives to resources

It is clear that the proposed legislation is concerned with the legalities of involuntary detention, and not with the methods whereby services are organised by the Health Boards. The White Paper does not concern itself with whether or not psychiatrists in general adult practice, or those specialising in child psychiatry, should take responsibility for the 16-18 year age group; but, by defining the age of childhood as "0-18 years for the purposes of detention", and by recommending that the 'child psychiatrist' should make the necessary involuntary detention recommendations to the Court, it certainly implies that the child psychiatric consultant should take the responsibility for this age group.

At present the only facilities available for a $171 / 2$-year-old are under the control of psychiatrists in general adult practice. There are no child psychiatrists with facilities for this age group. A very practical problem therefore arises in relation to the wording in the White Paper whereby the "Consultant Psychiatrist. . . specialising in the care of children" has to make the recommendation to the Court for a $17^{1 / 2} / 2$-year-old's involuntary admission.

It is already a serious concern for child and adolescent psychiatrists that they face the prospect of suit in respect of possible negligence in that they do not have the resources at present for therapeutic interventions they frequently define and prescribe. The additional 16-18 year age group will make matters even more difficult.

Why must the courts always be involved?

In a situation where there is parental consent and the younger child is refusing treatment, we fail to see why, if there is parental consent for a child's involuntary detention for treatment, the same procedures as apply to adult involuntary detention orders should not apply in child psychiatric practice. There is no age attaching to involuntary detention orders under the UK Mental Treatment Acts. In view of the White Paper's stated aim to "provide for the closest possible coordination of the two systems of Law for the detention. . . etc." between Northern Ireland and the Republic (11.19), we are at a loss to understand the cumbersome system proposed.

Not only do we believe that it would be best that adult-style involuntary detention orders should be available for child practice, but we also believe that, in order to safeguard their civil liberties, children of all ages should have automatic right of appeal to a mental health review tribunal. This tribunal should include a child psychiatrist.

We do indeed agree that the courts should be involved if parents refuse consent, and we also acknowledge that older adolescents (e.g. 15-18 years) may require the court to adjudicate their competence to refuse treatment; but there should be a 'cut-off point' of perhaps 14 years of age, below which children should routinely accept parental decisions. 
Personality disorders, deviant social

behaviour, addiction

When a child or adolescent's severe conduct disorder is clearly causally related to underlying mental illness (or to a previously unrecognised major family or peer-group problem, for example sexual abuse), child psychiatry has much to offer, but many conduct disordered youngsters do not need (or respond to) psychiatric teatment. They need instead a time of secure care in either the juvenile justice system, or the community child care services.

Whether or not a child should be involuntarily detained under the Mental Health Act should be, in this particular instance, very much determined by the psychiatrist of the specialised children's unit.

Juvenile Justice Bill and also amendments to Children's Act 1991

Apart from the need to develop the necessary resources (both in hospital units and skilled professional personnel), the satisfactory implementation of this new Mental Health Act will be very much determined by the passage of the legislation indicated in this heading. There is a concern that attempts might be made to contain out-of-control teenagers under mental health legislation in the absence of suitable provisions in law to otherwise cater for their needs for safety and containment.

\section{Services for the elderly and demented (Chapters 2 and 3)}

The Irish Division welcomes the manner in which dementia is defined for the purpose of detention. With regard to Dementia Centres, the recommendation that people be detained in a centre specialising in the care of persons with dementia is not based on current clinical practice. A psychiatry of old age unit adjacent to or in a defined area of the acute general psychiatric unit is preferable. This would enable both dementia sufferers and elderly people with functional psychiatric disorders, both of which come within the remit of psychiatry of old age services, to have access to acute treatment facilities.

\section{Services for the mentally handicapped (Chapters 2 and 3)}

The Irish Division supports the broad definition of the term mental disorder, including as it does significant mental handicap. The Division also welcomes recognition of a centre for people with mental handicap as a place of detention. With regard to children and young people, again it is important that issues relating to young persons will be equally relevant to mentally handicapped children and young people. We recommend that in the case of people with mental handicap that a member of the Review Board should have some experience in the field. Many mentally handicapped persons are unable to give informed consent or to understand treatment issues. In principle the Division believes that they should give consent whenever it is possible and that the rules for ECT for people with mental handicap should be similar to those for other patients. However, it is our view that this area regarding consent in general for people with mental handicap requires elucidation. The Mental Handicap Section of the Irish Division welcomes the provision of adult Care Orders for those who are mentally handicapped who are being abused, neglected or exploited. Procedures such as seclusion and restraint are used in Mental Handicap Centres for a small but particularly problematic population. These procedures are undertaken with an accompanying strict Code of Practice.

\section{Resources}

The Irish Division is very concerned about the implication of new legislation for increased costs. The Mental Health Review Board and its panels in particular will be costly exercises, and it is vitally important for a continuation of good services that these costs will not be taken from the already scarce mental health budget. Legislation in relation to children will inevitably exacerbate the already urgent situation where inpatient facilities are required for disturbed children and adolescents. Especially where a degree of security is required, such young people are not appropriately treated in adult units or in the few open facilities for children.

Likewise, the desired provision of specialised centres for people with mental handicap and for the elderly will require adequate resources, and the much needed 'special centres', perhaps regional secure units, will be costly to provide and to maintain. New funding must be provided to upgrade the community psychiatric services in these ways.

Marcus Webb, Chairman of the Irish Division, Royal College of Psychiatrists, Whitaker House, 37 Carysfort Downs, Blackrock, Co. Dublin 